\title{
Glucose Production, Gluconeogenesis, and Insulin Sensitivity in Children and Adolescents: An Evaluation of Their Reproducibility
}

\author{
AGNETA L. SUNEHAG, MARGARITA S. TREUTH, GIANNA TOFFOLO, NANCY F. BUTTE, \\ CLAUDIO COBELLI, DENNIS M. BIER, AND MOREY W. HAYMOND \\ Children's Nutrition Research Center, Houston, Texas 77030, U.S.A. [A.L.S., M.S.T., N.F.B., D.M.B., \\ M.W.H.] and Department of Electronics and Informatics, University of Padua, Padua, Italy [G.T., C.C.]
}

\begin{abstract}
ABST
The prevalence of overweight and obese children has dou-
bled, and the incidence of type 2 diabetes in children $(0-19$ y)
has increased 4 -fold during the past several decades. As a result
we can anticipate an increased number of metabolic studies in
children. There are few data on measures of glucose metabolism
in normal children, and virtually none relating to their reproduc-
ibility. The aims of this study were 1$)$ to provide new data on
energy expenditure and glucose, lipid, and protein metabolism in
nonobese, healthy children and adolescents; 2$)$ to evaluate their
reproducibility; and 3$)$ on the basis of these data, to perform
power calculations for metabolic studies. Eight nonobese sub-
jects $(8-16$ y) were studied on two occasions, preceded by $7 \mathrm{~d}$ of
a diet with identical energy content and macronutrient distribu-
tion. Gluconeogenesis, measured by deuterium oxide, accounted
for $50 \%$ of glucose production. Insulin sensitivity, measured by
the labeled minimal model, averaged 4.9 $\times 10^{-4}$
mL(mU.min) ${ }^{-1}$. Glucose appearance rate was significantly
higher $(p<0.01)$ in the children than in the adolescents.
Furthermore, we demonstrated that for energy intake and expen-
diture, plasma concentrations of glucose and C-peptide, and rates
of appearance of glucose and leucine, a $10 \%$ difference can be
\end{abstract}
detected in fewer than five subjects with a power of $80 \%$ and a type I error of 5\%. Insulin concentration, gluconeogenesis, insulin secretory indices, insulin sensitivity, and glucose effectiveness were more variable, but with the above power a difference of $25 \%$ could be detected in 7-11 subjects using a paired study design. (Pediatr Res 50: 115-123, 2001)

Abbreviations
BMI, body mass index
BMR, basal metabolic rate
CV, coefficient of variation
GC, gas chromatography
GCMS, gas chromatography mass spectrometry
GPR, glucose production rate
HMT, hexamethylenetetramine
IVGTT, intravenous glucose tolerance test
KIC, $\alpha$-ketoisocaproic acid
RQ, respiratory quotient
Ra, rate of appearance
S $_{\mathbf{I}}$, insulin sensitivity
$\mathbf{S}_{\mathbf{G}}$, glucose effectiveness

For the past several decades, we have experienced a dramatic increase in the incidence of obesity, insulin resistance, and type 2 diabetes in children and adolescents in the United States. The prevalence of overweight children $(\mathrm{BMI}>85 \mathrm{th}$ percentile) has increased from approximately $15 \%$ to $22 \%$ and the prevalence of obesity $(\mathrm{BMI}>95$ th percentile) from $5 \%$ to $11 \%$ (1). Concomitant with this increase in weight, the inci-

Received August 23, 2000; accepted January 30, 2000.

Correspondence and reprint requests: Agneta L. Sunehag, M.D., Ph.D., Children's Nutrition Research Center, 1100 Bates Street, Houston, TX 77030, U.S.A.; e-mail: asunehag@bcm.tmc.edu

This work is a publication of the U.S. Department of Agriculture/Agricultural Research Service, Children's Nutrition Research Center, Department of Pediatrics, Baylor College of Medicine, Houston, Texas. This project was supported by grants from MARS inc. and U.S. Department of Agriculture Cooperative Agreement 58-6250-6-001. The contents of this publication do not necessarily reflect the views or policies of the U.S. Department of Agriculture, nor does mention of trade names, commercial products, or organizations imply endorsement from the U.S. government. dence of type 2 diabetes in a pediatric population (birth to age 19 y) increased from approximately 4\% before 1992 to approximately 16\% in 1994 (2). It has been recently estimated that $30 \%$ of the individuals presenting with diabetes in the second decade of life have type 2 diabetes (3). As a result of these frightening trends, we can anticipate an increased number of metabolic studies conducted in children and adolescents.

A variety of tools and techniques have been developed during the past decades to evaluate a wide spectrum of measures of glucose metabolism (4-11). These tools will become of increasing importance as clinical research is focused on the etiology and pathogenesis of obesity and type 2 diabetes. Because of the difficulty in studying normal children for technical and ethical reasons, few measurements of GPR and other metabolic variables in normal children have been used (4), and there are virtually no studies relating to the reproducibility of 
such measures in children. Although gluconeogenesis has been estimated in premature infants and adults $(6,8,12-15)$, no information is available about the fraction of glucose production derived from gluconeogenesis in children. The majority of studies on $\mathrm{S}_{\mathrm{I}}$ in children has been conducted using the unlabeled minimal model IVGTT or the euglycemic hyperinsulinemic clamp technique (16-20). The stable, labeled IVGTT (9) is more informative than the unlabeled IVGTT in that it distinguishes between the effect of insulin on hepatic glucose production and peripheral glucose uptake. However, we are aware of only one study using the labeled minimal model in children (21).

In designing research protocols, it is essential to make a power calculation to estimate the number of subjects needed for a particular study. The present study was conducted to obtain intra- and intersubject reproducibility measures on energy expenditure, glucose production, gluconeogenesis, insulin secretion, $\mathrm{S}_{\mathrm{I}}, \mathrm{S}_{\mathrm{G}}$, lipolysis, and proteolysis in children and adolescents for just such a purpose.

\section{METHODS}

\section{Subjects}

The protocol was approved by the Institutional Review Board for Human Subject Research for Baylor College of Medicine and affiliated hospitals. The subjects were recruited by local advertisement. Attempts were made to recruit from all ethnic groups. Several potential subjects were excluded on the basis of body fat criteria, resulting in the ultimate recruitment of six white, one African-American, and one Asian subjects. All children signed assent and their parents, informed consent. Eight children, four prepubertal (Tanner pubertal stage 1) (22) and four postpubertal (Tanner pubertal stage 5) (22), two boys and two girls in each group, were studied on two occasions (Table 1). We did not include any early or mid-pubertal children, because puberty is associated with decreased $\mathrm{S}_{\mathrm{I}}$. Thus, advancing puberty would have confounded our ability to compare data over time and among individuals. All children were healthy as determined by a standard medical history, a physical examination, and standard blood chemistry. They were all selected for normal weight-for-height (23) and for normal body composition, defined as $<28 \%$ body fat determined by dual-energy x-ray absorptiometry (Hologic QDR 2000, Hologie, Inc., Waltham, MA, U.S.A.) (Table 1) and a BMI between 18 and $26 \mathrm{~kg} / \mathrm{m}^{2}$ (24). The dual-energy x-ray absorptiometry allows for analysis of total and regional lean tissue mass, bone mineral content, and fat mass. Fat-free mass is defined as the sum of lean tissue mass and bone mineral content. Subjects were excluded if they had obese parents $\left(\mathrm{BMI}>28 \mathrm{~kg} / \mathrm{m}^{2}\right)$ or a first-degree relative with diabetes.

\section{Study Design}

The children were admitted to the metabolic research unit at the Children's Nutrition Research Center for $2 \mathrm{~d}$ on two occasions separated by $2-8 \mathrm{wk}$. For the $7 \mathrm{~d}$ before each study occasion, the children received a constant diet of known composition, $60 \%$ carbohydrate, $15 \%$ protein, and $25 \%$ fat (Table 2). The total energy intake and distribution of energy from carbohydrate, fat, and protein were analyzed using the Minnesota Database System (version 2.8 NDS, Minneapolis, MN, U.S.A.). According to reported values of physical activity, total energy intake for each individual subject was set as a multiple of 1.7 to $2.0 \times$ BMR, predicted from weight and age according to Schofield (25). Three meals and two snacks per day were weighed, prepacked, and sent to the subject's home by the research kitchen. Unconsumed food was returned to the kitchen and examined for constituents, and the energy and macronutrient composition of the consumed food was calculated by difference (Table 2). A dietitian was in daily telephone contact with the families to evaluate the children's compliance with the diet.

Following the 7-d diet period at home, the subjects were admitted to the metabolic research unit. In the afternoon of the day of admission (d 1), the subjects were placed in a room calorimeter to assess 24-h energy expenditure. The calorimeter design characteristics have been previously described in detail (26). Three electrodes were applied to the child's skin, and the heart rate was recorded by telemetry at 1-min intervals (DS3000, Fukuda Denshi, Tokyo, Japan). Two 20-min exercise sessions were conducted on stationary bicycles (CombiCycle Ex80, COBI, Co, Ltd, Tokyo, Japan) at workloads approximating 40 and $60 \%$ of the child's peak oxygen consumption. After fasting overnight $(12 \mathrm{~h})$, the subject was awakened at $0630 \mathrm{~h}$ (on d 2), asked to void, and returned to sleep. The child was again awakened about $30 \mathrm{~min}$ later, and after confirmed awake, BMR was measured for $40 \mathrm{~min}$, beginning at $0720 \mathrm{~h}$. The child was monitored both visually and by the activity sensor to confirm that he or she was lying still ( $<50$ counts) for the entire measurement period. BMR, sleeping metabolic rate,

Table 1. Subjects

\begin{tabular}{|c|c|c|c|c|c|c|}
\hline Subject & Age & Sex & Tanner stage & $\begin{array}{l}\text { Weight } \\
(\mathrm{kg})\end{array}$ & Height $(\mathrm{cm})$ & $\begin{array}{c}\text { DXA \% } \\
\text { fat }\end{array}$ \\
\hline 1 & 9 & $\mathrm{~F}$ & 1 & 27.0 & 127.6 & 20.8 \\
\hline 2 & 9 & $\mathrm{~F}$ & 1 & 27.2 & 139.5 & 15.8 \\
\hline 4 & 9 & M & 1 & 36.4 & 140.5 & 23.9 \\
\hline 5 & 16 & M & 5 & 70.0 & 176.6 & 6.6 \\
\hline 6 & 14 & $\mathrm{~F}$ & 5 & 46.8 & 160.8 & 23.0 \\
\hline Mean $\pm \mathrm{SEM}$ & $12 \pm 2$ & & & $46.7 \pm 6.2$ & $153.8 \pm 6.7$ & $18.1 \pm 2.2$ \\
\hline
\end{tabular}

DXA, dual-energy x-ray absorptiometry. 
and 24-h energy expenditure were calculated using the de Weir equation (27).

During the calorimeter tests, the children were fed a diet of equal composition as during the week preceding the study, except the total energy content was decreased to 1.4 to $1.5 \times$ BMR to adjust for a lower activity level (Table 2). Net fat and carbohydrate utilization was computed using 24-h excretion rates of urinary nitrogen. After completion of the calorimeter test (in the afternoon on study d 2), the subjects were served dinner at $1700 \mathrm{~h}$ and a snack at $2000 \mathrm{~h}$ and were subsequently fasted until termination of the study on $\mathrm{d} 3$. Subjects were allowed water ad libitum throughout the study. In the evening on study d 2, two i.v. catheters were placed under Emla cream analgesia, one in an antecubital vein for infusion and one in the opposite antecubital vein or a vein on the opposite hand for blood sampling.

\section{Tracer Infusions}

Tracers. Deuterium oxide (99\% atom $\left.\%{ }^{2} \mathrm{H}\right),\left[{ }^{2} \mathrm{H}_{5}\right]$ glycerol $\left(99 \%\right.$ atom \% $\left.\left[{ }^{2} \mathrm{H}\right] ; 93.5 \%\left[{ }^{2} \mathrm{H}_{5}\right]\right),\left[1-{ }^{13} \mathrm{C}\right]$ glucose $(99 \%$ atom $\left.\%\left[{ }^{13} \mathrm{C}\right]\right) ;\left[6,6-{ }^{2} \mathrm{H}_{2}\right]$ glucose $\left(99 \%\left[{ }^{2} \mathrm{H}\right] ; 98 \%\left[{ }^{2} \mathrm{H}_{2}\right]\right)$, and $\left[{ }^{2} \mathrm{H}_{3}\right]$ leucine $\left(99 \%\left[{ }^{2} \mathrm{H}\right] ; 97 \%\left[{ }^{2} \mathrm{H}_{3}\right]\right)$ were purchased from Cambridge Isotope Laboratories (Andover, MA, U.S.A.). The isotopes were tested for sterility and pyrogenicity by the investigation pharmacy at Texas Children's Hospital. The infusates were filtered through a Gelman (Pall Gelman Laboratory, Ann Arbor, MI, U.S.A.) syringe filter $(2 \mu \mathrm{m})$ and were stored at $4^{\circ} \mathrm{C}$ for $24-48 \mathrm{~h}$ before administration.

On study d 2, the subjects received a total of $3 \mathrm{~g} / \mathrm{kg}$ of deuterium oxide, administered in five doses at $1400 \mathrm{~h}, 1600 \mathrm{~h}$, $1800 \mathrm{~h}, 2000 \mathrm{~h}$, and $2200 \mathrm{~h}$, to measure gluconeogenesis. On study d 3, between $0600 \mathrm{~h}$ and $1300 \mathrm{~h}$, the subjects received a simultaneous, primed $(60 \times$ the minute infusion rate), constant rate i.v. infusion of $\left[1-{ }^{13} \mathrm{C}\right]$ glucose, $\left[{ }^{2} \mathrm{H}_{5}\right]$ glycerol, and $\left[{ }^{2} \mathrm{H}_{3}\right]$ leucine. The $\left[1-{ }^{13} \mathrm{C}\right]$ glucose was infused at a rate of 0.66 $\pm 0 \mu \mathrm{mol} \cdot \mathrm{kg}^{-1} \cdot \mathrm{min}^{-1}$ (mean $\pm \mathrm{SEM}$ ) in prepubertal children and $0.33 \pm 0 \mu \mathrm{mol} \cdot \mathrm{kg}^{-1} \cdot \mathrm{min}^{-1}$ in adolescents, $\left[{ }^{2} \mathrm{H}_{5}\right]$ glycerol

Table 2. Energy intake and distribution at home $\left(E I_{H}\right)$ and in the calorimeter $\left(E I_{C}\right)$, energy expenditure in the calorimeter $\left(E E_{C}\right)$, substrate utilization, nonprotein $R Q$, and $B M R^{*}$

\begin{tabular}{lcc}
\hline & Study 1 & Study 2 \\
\hline $\mathrm{EI}_{\mathrm{H}}\left(\mathrm{EI}_{\mathrm{C}}\right)(\mathrm{kcal} / \mathrm{d})$ & $2252 \pm 255$ & $2311 \pm 246$ \\
& $(1864 \pm 160)$ & $(1857 \pm 156)$ \\
Energy distribution \% of $\mathrm{EI}_{\mathrm{H}}\left(\%\right.$ of $\left.\mathrm{EI}_{\mathrm{C}}\right)$ & & \\
$\quad$ Protein & $15.2 \pm 0.3$ & $15.4 \pm 0.3$ \\
& $(15.2 \pm 0.3)$ & $(15.6 \pm 0.2)$ \\
Fat & $24.9 \pm 0.3$ & $25.0 \pm 0.4$ \\
& $(25.3 \pm 0.4)$ & $(25.6 \pm 0.5)$ \\
Carbohydrate & $61.7 \pm 0.6$ & $61.4 \pm 0.5$ \\
& $(60.8 \pm 0.6)$ & $(59.9 \pm 0.5)$ \\
EE $_{\mathrm{C}}(\mathrm{kcal} / \mathrm{d})$ & $1835 \pm 145$ & $1878 \pm 160$ \\
Substrate utilization \% of $\mathrm{EE}_{\mathrm{C}}$ & & \\
$\quad$ Protein & $19.0 \pm 1.5$ & $18.7 \pm 1.2$ \\
Fat & $28.2 \pm 2.9$ & $30.7 \pm 2.0$ \\
Carbohydrate & $65.0 \pm 3.7$ & $62.1 \pm 2.6$ \\
Nonprotein RQ & $0.89 \pm 0.01$ & $0.88 \pm 0.01$ \\
BMR (kcal/min) & $0.89 \pm 0.07$ & $0.91 \pm 0.07$ \\
\hline
\end{tabular}

* Values are mean $\pm \mathrm{SEM}$.

No comparison between study 1 and 2 was significantly different. was infused at $0.29 \pm 0.01 \mu \mathrm{mol} \cdot \mathrm{kg}^{-1} \cdot \mathrm{min}^{-1}$ and $0.14 \pm 0$ $\mu \mathrm{mol} \cdot \mathrm{kg}^{-1} \cdot \mathrm{min}^{-1}$ in the two groups, respectively, and leucine at $0.06 \pm 0 \mu \mathrm{mol} \cdot \mathrm{kg}^{-1} \cdot \mathrm{min}^{-1}$ in both groups. At $0900 \mathrm{~h}$, on study d 3 (after the 0-min blood sample, see below), a bolus injection of glucose, $0.30 \pm 0 \mathrm{~g} / \mathrm{kg}$ containing $10 \%[6,6-$ ${ }^{2} \mathrm{H}_{2}$ ]glucose, was administered for $90-120 \mathrm{~s}$.

Blood sampling. Blood samples $(2.5 \mathrm{~mL}$ each $)$ were obtained at the following times: 1 ) at screening, i.e. weeks before any tracer infusions (prebaseline); 2) before start of the tracer infusions, i.e. $7 \mathrm{~h}$ after the last dose of deuterium oxide (baseline); 3) every 10 min between 2.5 and $3 \mathrm{~h}$ after start of the tracer infusions; and 4) beginning exactly with the completion of the bolus injection ( $0 \mathrm{~min}$ ) and thereafter at 2, 3, 4, $5,8,10,18,20,28,32,40,60,120,180$, and $240 \mathrm{~min}(9)$, i.e. a total of 20 blood samples of $2.5 \mathrm{~mL}$, resulting in a blood loss of $50 \mathrm{~mL}$ per study occasion. The samples were analyzed as described in detail below.

\section{Analyses}

Plasma glucose concentrations were measured by a glucose analyzer (YSI 2300 Stat plus, Yellow Springs Instrument Co Inc., Yellow Springs, OH, U.S.A.). Plasma insulin and Cpeptide concentrations were analyzed using commercially available RIA kits (Linco, St. Charles, MO, U.S.A.). The detection limit for this RIA is $0.2 \mu \mathrm{U} / \mathrm{mL}$ for insulin and 0.1 $\mathrm{ng} / \mathrm{mL}$ for C-peptide.

\section{Plasma Isotopic Enrichments}

The pentaacetate derivative of glucose was prepared as previously described $(28,29)$, and the $\left[1-{ }^{13} \mathrm{C}\right]$ glucose enrichment was analyzed by GC-combustion-isotope ratio mass spectrometry using an HP5890 GC (GC column: DB 1701, $25 \mathrm{~m} \times$ $0.25 \mathrm{~mm} \times 0.25 \mu \mathrm{m} ; \mathrm{J} \& \mathrm{~W}$ Scientific Inc., Folsom, CA, U.S.A.) combined with an Orchid combustion oven and a 20-20 analyzer from Europa Scientific (Franklin, OH, U.S.A.). In addition, the $(\mathrm{M}+1)$ and $(\mathrm{M}+2)$ isotopomers of glucose were analyzed by GCMS (HP5890/5989B; GC column DB $1701,25 \mathrm{~m} \times 0.25 \mathrm{~mm} \times 0.25 \mu \mathrm{m}$ ) using the electron impact mode and a fragment from which glucose carbon-1 is cleaved. Thus, the isotopic contribution from $\left[1-{ }^{13} \mathrm{C}\right]$ glucose is minimized. The ions monitored were 242 , representing unlabeled glucose, 243, representing glucose derived from deuterium oxide, and 244 , derived from 1 ) the $\left[6,6-{ }^{2} \mathrm{H}_{2}\right]$ glucose tracer, 2) $\left[{ }^{2} \mathrm{H}_{5}\right]$ glycerol via gluconeogenesis, and 3) deuterium oxide. One hydrogen/deuterium atom is lost in the conversion of glycerol-3-phosphate to dihydroxyacetone phosphate, a second in the formation of fructose-1,6-diphosphate from glyceraldehyde-3-phosphate and dihydroxyacetone phosphate, and a third in the conversion of fructose-6-phosphate to glucose-6phosphate. Therefore, the $\left[{ }^{2} \mathrm{H}_{5}\right]$ glycerol tracer results in an $(\mathrm{M}+2)$ isotopomer of glucose when glycerol is converted to glucose via the gluconeogenic pathway.

The ${ }^{2} \mathrm{H}$-enrichment in glycerol was measured using a modification of the previously described triacetate derivative (28, 29), substituting propionic anhydride for acetic anhydride. An internal standard $\left(\left[2-{ }^{13} \mathrm{C}\right]\right.$ glycerol $]$ (99 atom $\%{ }^{13} \mathrm{C}$; Cambridge Isotope Laboratories) was added to the plasma samples to 
measure glycerol concentration using reverse isotope dilution. The ${ }^{2} \mathrm{H}$ - and ${ }^{13} \mathrm{C}$-glycerol enrichments were analyzed by GCMS (HP6890/5973; GC column, SP 17: $25 \mathrm{~m} \times 0.25 \mathrm{~m} \times$ $0.25 \mu \mathrm{m}$; Supelco, Bellefonte, PA, U.S.A.) in the electron impact mode by selective monitoring of $\mathrm{m} / \mathrm{z} 173$, unlabeled glycerol; $\mathrm{m} / \mathrm{z} 174$, representing the internal standard; and $\mathrm{m} / \mathrm{z}$ 176 , representing ${ }^{2} \mathrm{H}_{3}$-enriched glycerol as a result of the loss of carbon 1 with its attachments during the fragmentation in the mass spectrometer. Leucine turnover was calculated from the $\left[{ }^{2} \mathrm{H}_{3}\right]$ enrichment of KIC (the intracellular metabolite of leucine). The oxime-terbutyldimethylsilyl derivative of KIC was prepared, and the $\left[{ }^{2} \mathrm{H}_{3}\right] \mathrm{KIC}$ enrichment was measured by GCMS (HP6890/5973; GC column, SP 1701: $25 \mathrm{~m} \times 0.25 \mathrm{~m}$ $\times 0.25 \mu \mathrm{m}$; Supelco), using the electron impact mode with selective monitoring of $\mathrm{m} / \mathrm{z} 316$, unlabeled KIC; $319,\left[{ }^{2} \mathrm{H}_{3}\right]-$ labeled KIC; and 323, representing the internal standard $\left[{ }^{2} \mathrm{H}_{7}\right] \mathrm{KIC}$ (used to measure plasma concentrations of KIC).

Deuterium incorporation at carbon 6 of glucose after ingestion of deuterium oxide was determined using the HMT derivative as described by Kalhan et al. (30). The Hickman still (Weaton, Millville, NJ, U.S.A.) was, however, modified by a glass blower, who enlarged the middle part of the neck of the still. This modification prevents the solution to be distilled from "bumping" into the collection portion of the still and enables us to successfully distill approximately 20 samples simultaneously. The deuterium enrichment in HMT was analyzed by GCMS (HP6890/5973; GC column, HP 5: $25 \mathrm{~m} \times$ $0.25 \mathrm{~mm} \times 1.0 \mu \mathrm{m}$, Hewlett Packard Co, Palo Alto, CA, U.S.A.) in the electron impact mode with selected monitoring of $\mathrm{m} / \mathrm{z} 140$ and 141. HMT enrichments were converted to the corresponding glucose enrichments using a standard curve prepared from $\left[1-{ }^{2} \mathrm{H}_{1}\right]$ glucose (99 atom $\%{ }^{2} \mathrm{H}$, Cambridge Isotope Laboratories) after conversion to sorbitol (31). Deuterium enrichment in body water (represented by plasma water) was measured by isotope ratio mass spectrometry (Finnigan Delta-E, Finnigan MAT, San Jose, CA, U.S.A.) after reduction to hydrogen gas according to accepted methods $(10,32)$. The potential influence of the $\left[1-{ }^{13} \mathrm{C}\right]$ glucose tracer on the measurements of gluconeogenesis was evaluated in five additional adolescents $(14.0 \pm 0.5 \mathrm{y} ; 62.5 \pm 3.5 \mathrm{~kg} ; 169.1 \pm 1.2 \mathrm{~cm} ; 21.9$ $\pm 1.3 \mathrm{~kg} / \mathrm{m}^{2} ; 16.1 \pm 1.4 \%$ body fat). These subjects were studied twice. On one occasion they received $\left[1{ }^{13} \mathrm{C}\right]$ glucose alone and on the other both $\left[1-{ }^{13} \mathrm{C}\right]$ glucose and deuterium oxide. The HMT was prepared from the samples obtained at the two study occasions, and fractional gluconeogenesis was calculated (30). The results show that the $\left[1{ }^{13} \mathrm{C}\right]$ glucose contribution to the $(\mathrm{M}+1)$ enrichment of HMT resulted in an overestimation of gluconeogenesis by $2.9 \pm 0.7 \%$ (range, 1.2-5.1\%). We consider this error to be clinically insignificant.

\section{Calculations}

During the period after 2.5 to $3 \mathrm{~h}$ of isotope infusion, approximate steady state (defined by a CV of $\leq 10 \%$ with a slope not different from 0) was achieved for plasma concentrations and isotopic enrichments of the substrates analyzed (steady-state measurement period). Substrate appearance rates were calculated from the average enrichment obtained for each substrate during this period using conventional tracer dilution techniques $(33,34)$. Thus, plasma glucose Ra were calculated from the ${ }^{13} \mathrm{C}$ enrichments of glucose, plasma glycerol Ra from the $\left[{ }^{2} \mathrm{H}_{3}\right]$ glycerol enrichment (12), and plasma leucine $\mathrm{Ra}$ from the $\left[{ }^{2} \mathrm{H}_{3}\right]$ KIC enrichment (12). Plasma concentrations of glycerol and KIC were calculated from the ion current ratio 174/ 173 and 323/316, respectively, using reverse isotope dilution.

Gluconeogenesis as a fraction of glucose Ra (equivalent to GPR) was calculated from the mean of the deuterium enrichments at the sixth carbon of glucose during the steady-state measurement period according to Kalhan et al. (30).

The gluconeogenic contribution from glycerol was calculated from the average fractions of the $(\mathrm{M}+2)$ isotopomer of glucose obtained during the steady-state measurement period after subtracting the fraction of $(\mathrm{M}+2)$ of glucose measured in the baseline sample (representing the contribution from deuterium oxide). This estimate represents the minimal gluconeogenic contribution from glycerol. The maximal contribution would correspond to $1 / 2 \times$ glycerol $\mathrm{Ra}$ assuming that all glycerol generated via lipolysis was converted to glucose. $\mathrm{S}_{\mathrm{I}}$ and $\mathrm{S}_{\mathrm{I}} *$ (the sensitivity of glucose disposition to insulin) and $\mathrm{S}_{\mathrm{G}}$ and $\mathrm{S}_{\mathrm{G}} *$ (the effect of glucose per se on its own disposition at basal insulin concentrations) were calculated both using the unlabeled minimal model (11) based on glucose and insulin concentrations of the samples obtained after the glucose bolus, and the labeled minimal model (35) based on tracer, i.e. exogenous glucose, and insulin data, respectively. We define, as in previous work (36-38), tracer as the exogenous glucose $(\mathrm{g})$, tracee as the endogenous glucose $\left(\mathrm{G}_{\text {end }}\right)$, and tracer to tracee ratio (ttr) as their ratio. Tracer glucose for the minimal model identification can be easily derived from total glucose measurements $(\mathrm{G})$ and $\mathrm{ttr}$, as from

$$
\mathrm{G}=\mathrm{G}_{\mathrm{end}}+\mathrm{g}
$$

and

$$
\operatorname{ttr}=\frac{\mathrm{g}}{\mathrm{G}_{\mathrm{end}}}
$$

it follows that

$$
g=G_{\frac{t t r}{(1+t t r)}}
$$

To calculate ttr during a stable labeled IVGTT, in Cobelli et al. (38), we used the formula derived in Cobelli et al. $(36,37)$, based on isotope ratios $r^{(2)}$ (i.e. the ratio between [6,6${ }^{2} \mathrm{H}_{2}$ ]glucose and $\left[6,6-{ }^{1} \mathrm{H}_{2}\right]$ glucose) and $r^{(1)}$ (i.e. the ratio between $\left[6-{ }^{2} \mathrm{H}_{1}, 6-{ }^{1} \mathrm{H}_{1}\right]$ glucose and $\left[6,6-{ }^{1} \mathrm{H}_{2}\right]$ glucose). Here, a different approach is used, which combines the relation between ttr and isotope ratios used in Cobelli et al. (38) with the relation between isotope ratios and the original mass spectrometry measurements, i.e. ion current ratios, to express ttr directly from ion current ratios:

$$
\operatorname{ttr}=\frac{\left(p^{(2)}-p_{\mathrm{ss}}^{(2)}\right)}{\left(p_{\mathrm{i}}^{(2)}-p^{(2)}\right)} \times \frac{\left(1+r_{\mathrm{i}}^{(1)}+r_{\mathrm{i}}^{(2)}\right)}{\left(1+r_{\mathrm{n}}^{(1)}+r_{\mathrm{n}}^{(2)}\right)}
$$


In Eq. $4, p^{(2)}$ is the ion current ratio $244 / 242$ in a sample taken during the experiment. To eliminate interference from any $(\mathrm{M}+2)$ glucose isotopomer generated by deuterium oxide and $\left[{ }^{2} \mathrm{H}_{5}\right]$ glycerol, $p_{\mathrm{ss}}{ }^{(2)}$ is represented by the average value of the ion current ratio 244/242 obtained during the steady-state measurement period. The error introduced by using this value for $p_{\mathrm{ss}}{ }^{(2)}$ was evaluated in the five additional adolescents who received deuterium oxide and $\left[{ }^{2} \mathrm{H}_{5}\right]$ glycerol as described above in the study design, in which the labeled glucose bolus was replaced by an unlabeled glucose bolus. This enabled us to follow the course of the $(\mathrm{M}+2)$ of glucose during the IVGTT. During the period 2-8 min after infusion of the IVGTT bolus, the concentrations of glucose and insulin are at their peak values. As a consequence, during this period, the suppression of glucose production and gluconeogenesis should reach a maximum, and the $(\mathrm{M}+2)$ of glucose derived from deuterium oxide or $\left[{ }^{2} \mathrm{H}_{5}\right]$ glycerol via the gluconeogenic pathway should reach its lowest value. The results from our control study demonstrate that during the period 2-8 min after the glucose bolus, the $(\mathrm{M}+2)$ of glucose was lower than that obtained during the steady-state period immediately preceding the IVGTT glucose bolus. During the remaining $232 \mathrm{~min}$ of the IVGTT sampling period, the $(\mathrm{M}+2)$ was similar to that obtained during the steady-state period. Thus, using the steadystate value for $p_{\mathrm{ss}}{ }^{(2)}$ would underestimate $244 / 242$ by at most $2.5 \%$ during the 2 - to 8 -min period after the IVGTT bolus. An error of this magnitude would not significantly interfere with the calculations of $\mathrm{S}_{\mathrm{I}}$ and $\mathrm{S}_{\mathrm{G}} \cdot p_{\mathrm{i}}^{(2)}$ is the ion current ratio $244 / 242$ in the tracer; $r_{\mathrm{n}}{ }^{(1)}$ and $r_{\mathrm{n}}{ }^{(2)}$ are tracee isotope ratios to be evaluated theoretically, from knowledge of the natural abundance (for $\left[6,6-{ }^{2} \mathrm{H}_{2}\right]$ glucose, $r_{\mathrm{n}}{ }^{(1)}=0.0003 ; r_{\mathrm{n}}{ }^{(2)}$ is negligible); $r_{\mathrm{i}}^{(1)}$ and $r_{\mathrm{i}}^{(2)}$ are tracer isotope ratios, to be calculated from natural and tracer ion current ratios 244/242 $\left(p_{\mathrm{n}}^{(2)}, p_{\mathrm{i}}^{(2)}\right)$ and $243 / 242\left(p_{\mathrm{n}}{ }^{(1)}, p_{\mathrm{i}}{ }^{(1)}\right)$ by using the following relations:

$$
\begin{gathered}
r_{\mathrm{i}}^{(1)}=r_{\mathrm{n}}{ }^{(1)}+p_{\mathrm{i}}{ }^{(1)}-p_{\mathrm{n}}{ }^{(1)} \\
r_{\mathrm{i}}{ }^{(2)}=r_{\mathrm{n}}{ }^{(2)}-\left(p_{\mathrm{n}}{ }^{(1)}-r_{\mathrm{n}}{ }^{(1)}\right)\left(p_{\mathrm{i}}{ }^{(1)}-p_{\mathrm{n}}{ }^{(1)}\right)+p_{\mathrm{i}}{ }^{(2)}-p_{\mathrm{n}}{ }^{(2)}
\end{gathered}
$$

The unlabeled minimal model cannot separate glucose production from glucose disposal. Therefore, this model describes the net hepatic glucose balance as a function of plasma glucose and insulin action, and $\mathrm{S}_{\mathrm{I}}$ and $\mathrm{S}_{\mathrm{G}}$ measure the effects of glucose and insulin on both glucose production (inhibition) and glucose disposal (stimulation). This limitation does not apply to the labeled minimal model, which measures the effect of glucose and insulin on glucose disposal alone $(9,35)$. $\beta$-Cell sensitivity indices during the IVGTT, related to the control of glucose on first $(\Phi 1)$ and second $(\Phi 2)$ phase secretions were estimated by using the minimal model C-peptide secretion and kinetics (39).

\section{Model Identification (labeled and unlabeled minimal models)}

Variables of the minimal models, together with their precision, were estimated by using the SAAMII software (40). Measurement errors have been assumed to be independent and to have a Gaussian distribution and a zero mean. Additional assumptions are that glucose concentration data have a constant $\mathrm{CV}$ equal to $2 \%$; tracer glucose concentrations (within the range $0.05-7.2 \mathrm{mM}$ ) have an experimentally determined $\mathrm{CV}$ with a typical range of $4-8 \%$; and C-peptide data have a constant SD which has been estimated a posteriori.

\section{Statistical Methods}

Data are presented as mean \pm SEM. Differences between values obtained on the two study occasions were tested by paired, two-tailed $t$ test. Differences between groups (glucose $\mathrm{Ra}$ and gluconeogenic rate) were tested by nonpaired, twotailed $t$ test. Power calculations were performed using the STAT PLAN software (Version 4.0: June 1993, Brown BW, Brauner C, Chan A, Gutierrez D, Herson J, Lovato J, Polsey J (eds), University of Texas, M.D. Anderson Cancer Center, Houston, TX, U.S.A.).

\section{RESULTS}

Subject characteristics, including age, weight, height, BMI, and percent fat, are depicted in Table 1, and the dietary intakes in Table 2. The consumed diet was equal on each study occasion both with regard to energy intake and distribution of carbohydrate, fat, and protein calories. In accordance with the study design, the calorimeter diet corresponded to $86 \pm 5 \%$ (study 1) and $83 \pm 4 \%$ (study 2) of the home diet, although the composition of the diet consumed in the calorimeter was virtually identical to the home diet (Table 2). The energy expenditure corresponded well to the energy intake in the calorimeter (Table 2). The results from the 24-h calorimeter test (Table 2) also show that RQ, BMR, and oxidation and utilization of carbohydrate, fat, and protein were not statistically different on the two study occasions.

Plasma concentrations of glucose, glycerol, insulin, and C-peptide during the steady-state measurement period (study hour 2.5 to 3) are depicted in Table 3, demonstrating that there were no differences between the two study occasions in either group.

\begin{tabular}{|c|c|c|c|c|c|c|c|c|}
\hline \multirow{2}{*}{$\begin{array}{l}\text { Study } \\
\text { group }\end{array}$} & \multicolumn{2}{|c|}{ [Glucose] (mM) } & \multicolumn{2}{|c|}{ [Glycerol] $(\mu \mathrm{M})$} & \multicolumn{2}{|c|}{ [Insulin] $(\mu \mathrm{U} / \mathrm{mL})$} & \multicolumn{2}{|c|}{ [C-peptide] (ng/mL) } \\
\hline & Study 1 & Study 2 & Study 1 & Study 2 & Study 1 & Study 2 & Study 1 & Study 2 \\
\hline $\begin{array}{l}\text { Prepubertal } \\
\text { children }\end{array}$ & $4.8 \pm 0.1$ & $4.8 \pm 0.1$ & $63 \pm 5$ & $68 \pm 4$ & $6.3 \pm 0.2$ & $6.7 \pm 0.2$ & $1.3 \pm 0.1$ & $1.3 \pm 0.1$ \\
\hline Adolescents & $4.7 \pm 0.1$ & $4.8 \pm 0.1$ & $61 \pm 4$ & $43 \pm 2$ & $6.9 \pm 0.7$ & $6.9 \pm 0.5$ & $1.8 \pm 0.3$ & $1.9 \pm 0.3$ \\
\hline All subjects & $4.7 \pm 0.1$ & $4.8 \pm 0.1$ & $62 \pm 6$ & $56 \pm 8$ & $6.8 \pm 0.9$ & $6.7 \pm 0.7$ & $1.6 \pm 0.2$ & $1.7 \pm 0.2$ \\
\hline
\end{tabular}

Table 3. Plasma concentrations of substrates and hormones during steady state (study $h 2.5$ to 3) 
Table 4. Isotopic enrichments during steady state (study h 2.5 to 3) for the whole study group $(n=8)$

\begin{tabular}{ccc}
\hline \multirow{2}{*}{ Tracer } & \multicolumn{2}{c}{ Enrichment $(\%)$} \\
\cline { 2 - 3 } & Study 1 & Study 2 \\
\hline$\left[1{ }^{13} \mathrm{C}\right]$ glucose & $3.0 \pm 0.1$ & $3.0 \pm 0.1$ \\
{$\left[{ }^{2} \mathrm{H}_{5}\right]$ glycerol } & $5.7 \pm 0.6$ & $6.7 \pm 0.7$ \\
$\left.{ }^{2} \mathrm{H}_{3}\right]$ KIC & $3.1 \pm 0.1$ & $3.1 \pm 0.1$ \\
${ }^{2} \mathrm{H}$ in body water & $0.40 \pm 0.01$ & $0.41 \pm 0.01$ \\
${ }^{2} \mathrm{H}$ in glucose $\mathrm{C} 6$ & $0.40 \pm 0.01$ & $0.40 \pm 0.01$ \\
\hline
\end{tabular}

Isotopic enrichments for $\left[1-{ }^{13} \mathrm{C}\right]$ glucose, $\left[{ }^{2} \mathrm{H}_{5}\right]$ glycerol, $\left[{ }^{2} \mathrm{H}_{3}\right] \mathrm{KIC}$, and ${ }^{2} \mathrm{H}$ in body water and glucose carbon 6 are depicted in Table 4. These enrichments were used to calculate glucose $\mathrm{Ra}$ (or GPR), glycerol Ra, leucine $\mathrm{Ra}$, fractional gluconeogenesis, and gluconeogenic rate, respectively. These results are reported in Table 5. There were no significant differences between the values obtained on the two study occasions for any of these variables. Total plasma glucose Ra was significantly higher $(p<0.05)$ in the adolescents, $789 \pm$ $43 \mu \mathrm{mol} / \mathrm{min}$ (mean of studies 1 and 2 in the adolescent group) than in the prepubertal children, $582 \pm 30 \mu \mathrm{mol} / \mathrm{min}$ (mean of studies 1 and 2 in the prepubertal group). However, when expressed per kilogram of body weight, glucose production was significantly higher $(p<0.01)$ in the prepubertal children compared with the adolescents, $18.5 \pm 0.9$ versus $13.0 \pm 0.6$ $\mu \mathrm{mol} \cdot \mathrm{kg}^{-1} \cdot \mathrm{min}^{-1}$, (mean of studies 1 and 2 within the two groups). Gluconeogenic rates expressed on a body weight basis were also significantly higher $(p<0.05)$ in the prepubertal children $\left(10.0 \pm 0.6 \mu \mathrm{mol} \cdot \mathrm{kg}^{-1} \cdot \mathrm{min}^{-1}\right.$ on both study occasions) when compared with those of the adolescents ( $6.7 \pm 0.6$ $\mu \mathrm{mol} \cdot \mathrm{kg}^{-1} \cdot \mathrm{min}^{-1}$, study 1 and $6.1 \pm 0.6 \mu \mathrm{mol} \cdot \mathrm{kg}^{-1} \cdot \mathrm{min}^{-1}$, study 2; Table 5).

Estimating gluconeogenesis from the deuterium enrichment at glucose carbon 6 represents gluconeogenesis from pyruvate and does not include the contribution from glycerol $(12,30)$. However, the glycerol contribution was calculated from the data obtained using the $\left[{ }^{2} \mathrm{H}_{5}\right]$ glycerol tracer (see Methods). Thus, glycerol contributed a minimum of $2.4 \pm 0.3 \%$ and 2.0 $\pm 0.3 \%$ of glucose production on study occasion 1 and 2 , respectively (NS). Assuming that all glycerol was converted to glucose, the maximal glycerol contribution to glucose production via gluconeogenesis would be $11.3 \pm 1.2 \%$ (study 1 ) and $9.4 \pm 1.2 \%$ (study 2 ; NS). Thus, the minimal total gluconeogenesis (pyruvate + glycerol) would be $54 \pm 3 \%$ (study 1 ) and $53 \pm 3 \%$ (study $2 ; \mathrm{NS}$ ), and maximal total gluconeogenesis, 63 \pm 2 (study 1 ) and $60 \pm 4 \%$ (study 2 ; NS). Figure 1 displays the concentrations of glucose, tracer glucose, insulin, and Cpeptide after the IVGTT bolus in studies 1 and 2 . The ability of the minimal model to describe glucose, tracer glucose, and C-peptide data is also shown in Figure 1, demonstrating that the values predicted by the model correspond well to the actual data. Table 6 demonstrates $\mathrm{S}_{\mathrm{I}}{ }^{*}$ and $\mathrm{S}_{\mathrm{I}}$ and $\mathrm{S}_{\mathrm{G}}{ }^{*}$ and $\mathrm{S}_{\mathrm{G}}$ calculated from the labeled and unlabeled models, respectively, and first- and second-phase insulin secretion indices ( $\Phi 1$ and $\Phi 2)$ calculated from the C-peptide model. The average precision with which $\mathrm{S}_{\mathrm{I}}$ * and $\mathrm{S}_{\mathrm{I}}$ were estimated, expressed as their CVs, were 22 and $47 \%$, respectively, for $\mathrm{S}_{\mathrm{G}}{ }^{*}$ and $\mathrm{S}_{\mathrm{G}}$, the CVs were 7 and $82 \%$, respectively, and for $\Phi 1$ and $\Phi 2,7$ and $16 \%$.

We have expressed the reproducibility of the above variables as 1$)$ the mean $\pm \mathrm{SD}(n=8)$ of the differences between the values obtained on each of the two study occasions in percent of the mean of these values (Table 7), and 2) the correlation between the values from study 1 and 2 (Table 7). Furthermore, based on the SD for the percent difference of the mean, we have performed power calculations (assuming a power of $80 \%$ and a type I error of 5\%) for each variable, i.e. we have calculated the number of subjects required to detect differences of 10 and $25 \%$, respectively, for each variable (Table 3 ). Thus, a $10 \%$ difference could be detected in five or fewer subjects for energy intake and expenditure, plasma concentrations of glucose and C-peptide, glucose Ra, and leucine Ra, whereas a $25 \%$ difference could be detected in 11 or fewer subjects for plasma insulin concentration, fractional gluconeogenesis, $\mathrm{S}_{\mathrm{I}}{ }^{*}$, $\mathrm{S}_{\mathrm{G}}{ }^{*}, \mathrm{~S}_{\mathrm{G}}, \Phi 1$, and $\Phi 2$. Glycerol turnover and $\mathrm{S}_{\mathrm{I}}$ (unlabeled minimal model) are more variable and required 16 and 18 subjects, respectively, to detect a $25 \%$ difference.

\section{DISCUSSION}

To our knowledge, this is the first study to report intraindividual reproducibility data for measures of glucose and insulin metabolism in children. Our results demonstrate that, using a prepacked meal strategy and frequent contacts with a dietitian, dietary macronutrient and energy intake can be controlled for a 7-d period in children in a free-living setting, and after a period of 2 to $8 \mathrm{wk}$ the dietary composition can be reproduced. Under these study conditions, in a sample of eight children, differences as small as $2-7 \%$ could be detected with a power of $80 \%$ and a type I error of $5 \%$ for measurements of energy intake and expenditure, plasma concentrations of glucose and C-peptide, rates of glucose appearance (and thus disappearance), and proteolysis (represented by leucine turnover) (Table 7). The fraction of glucose derived from gluconeogenesis,

Table 5. Glucose Ra (equivalent to GPR), gluconeogenesis, glycerol Ra, and leucine Ra during steady state (study h 2.5 to 3)

\begin{tabular}{|c|c|c|c|c|c|c|c|c|c|c|}
\hline \multirow{2}{*}{$\begin{array}{l}\text { Study } \\
\text { group }\end{array}$} & \multicolumn{2}{|c|}{$\begin{array}{c}\mathrm{GPR} \\
\left(\mu \mathrm{mol} \cdot \mathrm{kg}^{-1} \cdot \mathrm{min}^{-1}\right)\end{array}$} & \multicolumn{2}{|c|}{$\begin{array}{c}\text { GNG rate } \\
\left(\mu \mathrm{mol} \cdot \mathrm{kg}^{-1} \cdot \mathrm{min}^{-1}\right)\end{array}$} & \multicolumn{2}{|c|}{ GNG \% GPR } & \multicolumn{2}{|c|}{$\begin{array}{c}\text { Glycerol Ra } \\
\left(\mu \mathrm{mol} \cdot \mathrm{kg}^{-1} \cdot \mathrm{min}^{-1}\right)\end{array}$} & \multicolumn{2}{|c|}{$\begin{array}{c}\text { Leucine Ra } \\
\left(\mu \mathrm{mol} \cdot \mathrm{kg}^{-1} \cdot \mathrm{min}^{-1}\right)\end{array}$} \\
\hline & Study 1 & Study 2 & Study 1 & Study 2 & Study 1 & Study 2 & Study 1 & Study 2 & Study 1 & Study 2 \\
\hline Adolescents & $12.9 \pm 0.4$ & $13.1 \pm 0.8$ & $6.6 \pm 0.7$ & $6.1 \pm 0.5$ & $51 \pm 6$ & $47 \pm 5$ & $2.8 \pm 0.3$ & $2.1 \pm 0.1$ & $1.9 \pm 0.1$ & $1.8 \pm 0.1$ \\
\hline All subjects & $15.8 \pm 1.2$ & $15.7 \pm 1.2$ & $8.2 \pm 0.7$ & $7.9 \pm 0.8$ & $52 \pm 3$ & $50 \pm 3$ & $3.5 \pm 0.5$ & $3.0 \pm 0.4$ & $1.9 \pm 0.1$ & $1.9 \pm 0.1$ \\
\hline
\end{tabular}

$* p<0.01, * * p<0.05$ prepubertal children $v s$ adolescents.

GNG, gluconeogenesis. 

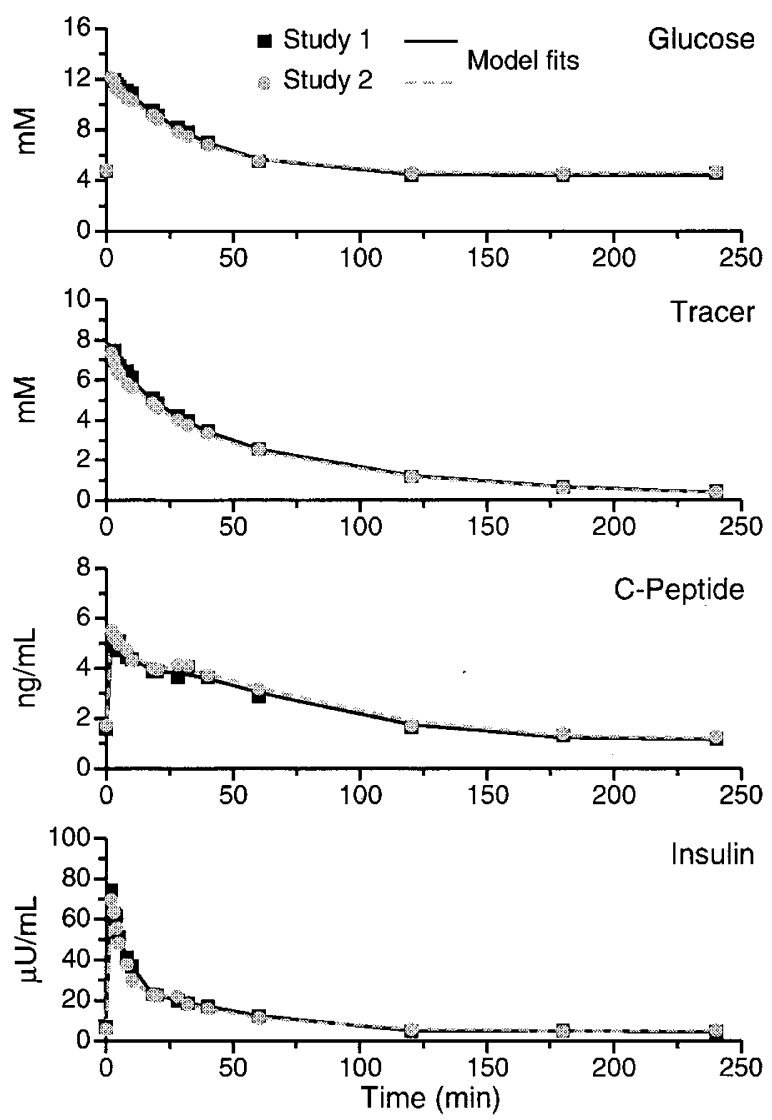

Figure 1. Concentrations of glucose, tracer glucose, insulin, and C-peptide and the minimal model fit after the IVGTT bolus in studies 1 and 2 .

plasma concentrations of insulin, $\mathrm{S}_{\mathrm{I}}$ (as determined by the labeled minimal model), $\mathrm{S}_{\mathrm{G}}$, and indices of insulin secretion were somewhat more variable; however, even for these measures, differences of $15-25 \%$ could be detected in only eight subjects (Table 7). $\mathrm{S}_{\mathrm{I}}$ determined by the unlabeled minimal model and lipolysis requires a larger number of subjects, 16 and 18 , respectively, to detect a difference of $25 \%$ at the power described above. With the exception of lipolysis and insulin secretory index $\Phi 2$, the correlation coefficient between the values obtained on the two study occasions was high, ranging between 0.72 and 0.996 (Table 3 ). The greater variability for measurements of glycerol factors is not surprising, as glycerol $\mathrm{Ra}$ is increased dramatically with small changes of plasma catecholamine concentrations (41). Therefore, special precautions should be taken to achieve stable measurements of lipolysis (such as a quiet room and minimal disturbance of the subject).

The labeled minimal model provides information on the effect of insulin on peripheral glucose uptake in response to an i.v. glucose bolus, whereas the unlabeled minimal model cannot distinguish between the hepatic (suppression of glucose production) and peripheral effects (increasing the glucose uptake) of insulin. Our results also demonstrate that the labeled minimal model provides more precise and consistent results than the unlabeled model. Despite these advantages of the labeled model, we are only aware of one report on $\mathrm{S}_{\mathrm{I}}$ using the stable labeled minimal model in children (21). Hoffman and
Armstrong (21) compared $\mathrm{S}_{\mathrm{I}}$ in lean and obese children between 5 and $12 \mathrm{y}$ of age. They reported significantly higher $\mathrm{S}_{\mathrm{I}}$ in the lean children compared with the obese. Our $\mathrm{S}_{\mathrm{I}}$ values were within the range reported by Hoffman and Armstrong (21), although our mean value was somewhat lower. Decreased $\mathrm{S}_{\mathrm{I}}$ has been demonstrated in adolescents compared with prepubertal children (16-19). In the present study, $\mathrm{S}_{\mathrm{I}}$ was somewhat (but not significantly) higher in prepubertal children. However, the lack of significance may be owing to the small number of subjects in each group.

The brain weight of a 6- to 9-year-old is similar to that of an adolescent (1300 $\mathrm{g}$ in the children and $1400 \mathrm{~g}$ in the adolescents) (42). Thus, assuming similar glucose utilization per $100 \mathrm{~g}$ of brain tissue (approximately $20 \mu \mathrm{mol} / 100 \mathrm{~g}$ brain weight per minute) (43), total glucose utilization from brain metabolism would be similar in adolescents and children, 280 and $260 \mu \mathrm{mol} / \mathrm{min}$, respectively. However, the greater brain to body weight ratio in the young children (4\% compared with $2 \%$ in the adolescents) explains the greater glucose $\mathrm{Ra}$ in children when compared with adolescents when expressed on a body weight basis. The greater absolute rate of glucose $\mathrm{Ra}$ (in micromoles per minute) in the adolescents is most likely because of a larger nonbrain tissue mass (e.g. fat and muscle).

To our knowledge, these studies are the first to demonstrate that the rate of gluconeogenesis, on a body weight basis, is greater in children between the ages of 8 and $9 \mathrm{y}$ than in adolescents between the ages of 14 and $16 \mathrm{y}$, whereas the fraction of glucose production derived from gluconeogenesis was essentially identical between the two groups of subjects.

The deuterium oxide method with assessment of deuterium enrichment at carbon 6 of glucose does not include the gluconeogenic contribution from glycerol (12, 30). However, using the information obtained by the $\left[{ }^{2} \mathrm{H}_{5}\right]$ glycerol tracer, we could calculate the glycerol turnover rates, an indicator of lipolysis, as well as the minimal and maximal estimates of the fraction of glucose Ra derived from glycerol via the gluconeogenic pathway. These estimates were also highly reproducible. Using these minimal estimates would result in a minimal estimate of total fractional gluconeogenesis of approximately $53 \%$. A maximal estimate would be approximately $60 \%$, assuming that $100 \%$ of glycerol Ra was converted to glucose.

We could not demonstrate any significant relationships between measures of glucose and lipid metabolism and percent body fat, energy intake and expenditure, oxidation rates, or RQ. This is not surprising, as the subjects were all healthy and nonobese, and they were studied under strict dietary and experimental conditions. We did not compare boys and girls because of the small sample size (prepubertal children, two boys, two girls; adolescents, two boys, two girls). Except for the differences in glucose $\mathrm{Ra}$ and gluconeogenic rate described above, we could not demonstrate any significant differences for metabolic variables between prepubertal children and adolescents. This may be related to the small group sizes (four subjects in each group), but the study was not designed to compare the two groups.

In summary, we demonstrate, using a prepacked meal strategy as described, that it is possible to maintain a consistent dietary energy intake and composition for a period of $7 \mathrm{~d}$ with 
Table 6. $S_{I}^{*}$ and $S_{I}$ (labeled and unlabeled models, respectively), $S_{G} *$ and $S_{G}$ (labeled and unlabeled models, respectively), and $\Phi 1$ and $\Phi 2$ insulin secretion indices (C-peptide model)

\begin{tabular}{|c|c|c|c|c|c|c|c|c|c|c|c|c|}
\hline \multirow{2}{*}{$\begin{array}{l}\text { Study } \\
\text { group }\end{array}$} & \multicolumn{2}{|c|}{$\begin{array}{c}\mathrm{S}_{\mathrm{I}}^{*} \times 10^{-4} \\
\left(\mathrm{~min}^{-1}\right) /\left(\mu \mathrm{UmL}^{-1}\right)\end{array}$} & \multicolumn{2}{|c|}{$\begin{array}{c}\mathrm{S}_{\mathrm{I}} \times 10^{-4} \\
\left(\mathrm{~min}^{-1} /\left(\mu \mathrm{UmL}^{-1}\right)\right.\end{array}$} & \multicolumn{2}{|c|}{$\mathrm{S}_{\mathrm{G}} * \times 10^{-2}\left(\mathrm{~min}^{-1}\right)$} & \multicolumn{2}{|c|}{$\mathrm{S}_{\mathrm{G}} \times 10^{-2}\left(\mathrm{~min}^{-1}\right)$} & \multirow{2}{*}{$\begin{array}{c}\Phi 1 \\
\times 10^{-9} \\
\text { Study } 1\end{array}$} & \multirow{2}{*}{$\begin{array}{c}\Phi 1 \times 10^{-9} \\
\text { Study } 2\end{array}$} & \multirow{2}{*}{$\begin{array}{c}\Phi 2 \times 10^{-9} \\
\min ^{-1} \\
\text { Study } 1\end{array}$} & \multirow{2}{*}{$\begin{array}{c}\Phi 2 \times 10^{-9} \\
\min ^{-1} \\
\text { Study } 2\end{array}$} \\
\hline & & & & & & & & & & & & \\
\hline & & & & & & & & & & & & \\
\hline All subjects & $.5 \pm 0.8$ & $.2 \pm 0.8$ & $.7 \pm 0.9$ & $4.6 \pm 0.8$ & $1.2 \pm 0.1$ & $1.1 \pm 0.1$ & $1.6 \pm 0.3$ & $1.8 \pm 0.3$ & $254 \pm 45$ & $258 \pm 36$ & $12.8 \pm 0.4$ & $5.7 \pm 1.6$ \\
\hline
\end{tabular}

Table 7. Calculations of population size required detecting a 10 and $25 \%$ difference at a power of $80 \%$ and a type I error of $5 \%$

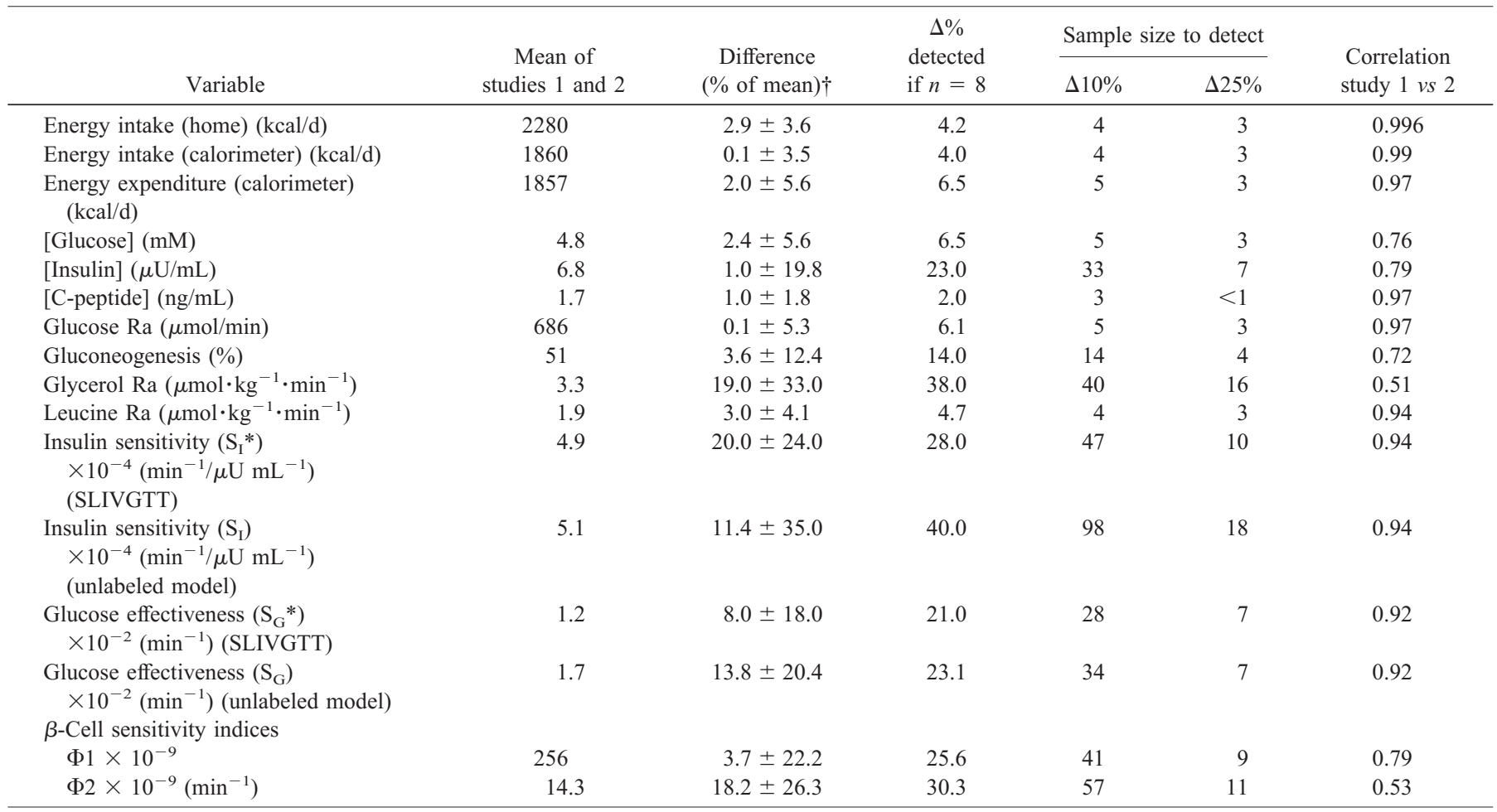

$\dagger 100 \times[($ study $1-$ study 2$)] /($ mean of studies 1 and 2$)$.

SLIVGTT, stable labeled IVGTT.

the children carrying out their normal activities. Furthermore, using our study design, it is possible to provide highly reproducible data on a number of measures of glucose metabolism. The power calculations performed on the basis of these data will enable us and other investigators to more precisely design studies to evaluate the impact of various treatments and dietary intervention strategies in children (e.g. children and adolescents with obesity and/or type II diabetes).

Acknowledgments. The authors thank research nurse Leah Mitchell, dietitian Sandy Kattner, and the staff of the Metabolic Research Unit at the Children's Nutrition Research Center, as well as Judy Rosenberg, Reed Parson, Carlotta Williams, Jiang-Ping Wen, Anne Adolph, Maurice Puyau, Firoz Vohra, and Nitesh Mehta for excellent assistance.

\section{REFERENCES}

1. Troiano RP, Flegal KM, Kuczmarski RJ, Campell SM, Johnson CL 1995 Overweight prevalence and trends for children and adolescents: The National Health and Nutrition Examination Surveys 1963 to 1991. Arch Pediatr Adolesc Med 149:1085-1091
2. Pinhas-Hamiel O, Dolan ML, Daniels SR, Standiford D, Khoury PR, Zeitler P 1996 Increased incidence of non-insulin-dependent diabetes mellitus among adolescents. J Pediatr 128:608-615

3. Rosenbloom AL, Joe JR, Young RS, Winter WE 1999 Emerging epidemic of type 2 diabetes in youth. Diabetes Care 22:345-354

4. Bier DM, Leake RD, Haymond MW, Arnold KJ, Gruenke LD, Sperling MA, Kipnis DM 1977 Measurement of "true" glucose production rates in infancy and childhood with 6,6-dideuteroglucose. Diabetes 26:1016-1023

5. Kalhan SC, Savin SM, Adam PAJ 1977 Estimation of glucose turnover with stable tracer glucose-1- ${ }^{13} \mathrm{C}$. J Lab Clin Med 89:285-294

6. Tayek JA, Katz J 1997 Glucose production, recycling, Cori cycle, and gluconeogenesis in humans relation to serum cortisol. Am J Physiol 272:E476-E484

7. Neese RA, Schwartz J-M, Faix D, Turner S, Letscher A, Vu D, Hellerstein MK 1995 Gluconeogenesis and intrahepatic triose phosphate flux in response to fasting or substrate loads. J Biol Chem 270:14452-14466

8. Landau BR, Wahren J, Chandramouli V, Schumann WC, Ekberg K, Kalhan SC 1995 Use of ${ }^{2} \mathrm{H}_{2} \mathrm{O}$ for estimating rates of gluconeogenesis. J Clin Invest 95:172-178

9. Cobelli C, Ruggeri A 1991 A reduced sampling schedule for estimating the parameters of the glucose minimal model from a labeled IVGTT. IEEE Trans Biomed Eng 38:1023-1029

10. Wong WW, Lee LS, Klein PD 1987 Deuterium and oxygen-18 measurements on microliter samples of urine, plasma, saliva, and human milk. Am J Clin Nutr 45:905-913

11. Bergman RN, Bowden CR, Cobelli C 1981 The minimal model approach to quantification of factors controlling glucose disposal in man. In: Cobelli C, Bergman RN (eds) Carbohydrate metabolism. Wiley Press, London, pp 269-296

12. Sunehag AL, Schanler RJ, Reeds PJ, Haymond MW, Bier DM 1999 Gluconeogenesis in very low birth weight infants receiving total parenteral nutrition. Diabetes 48:791800 
13. Katz J, Tayek JA 1998 Gluconeogenesis and the Cori cycle in 12-, 20-, and 40-h-fasted humans. Am J Physiol 275: E537-E542

14. Hellerstein MK, Neese RA, Linfoot P, Christiansen M, Turner S, Letscher A 1997 Hepatic gluconeogenic fluxes and glycogen turnover during fasting in humans: a stable isotope study. J Clin Invest 100:1305-1319

15. Landau BR, Wahren J, Chandramouli V, Schumann WC, Ekberg K, Kalhan SC 1996 Contributions of gluconeogenesis to glucose production in the fasted state. J Clin Invest 98:378-385

16. Lindgren F, Dahlquist G, Efendic S, Persson B, Skottner A 1990 Insulin sensitivity and glucose- induced insulin response changes during adolescence. Acta Pediatr Scand 79:431-436

17. Caprio S, Plewe G, Diamond MP, Simonson DC, Boulware SD, Sherwin RS, Tambolane W 1989 Increased insulin secretion in puberty: a compensatory response to reductions in insulin sensitivity. J Pediatr 114:963-967

18. Cook JS, Hoffman RP, Stene MA, Hansen JR 1993 Effects of maturational stage on insulin sensitivity during puberty. J Clin Endocrinol Metab 77:725-730

19. Travers SH, Jeffers BW, Bloch CA, Hill JO, Eckel RH 1995 Gender and Tanner stage differences in body composition and insulin sensitivity in early pubertal children. J Clin Endocrinol Metab 80:172-178

20. Gower BA, Nagy TR, Goran MI 1999 Visceral fat, insulin sensitivity, and lipids in pre-pubertal children. Diabetes 48:1515-1521

21. Hoffman RP, Armstrong PT 1996 Glucose effectiveness, peripheral and hepatic insulin sensitivity, in obese and lean pre-pubertal children. Int J Obes Relat Metab Disord 20:521-525

22. Tanner JM 1981 Growth and maturation during adolescence. Nutr Rev 39:43-55

23. Hamill PVV, Drizd TA, Johnson CL, Reed RB, Roche AF, Moore WM 1979 Physical growth: National Center for Health Statistics percentiles. Am J Clin Nutr 32:607-629

24. Rosner B, Prineas R, Loggie J, Daniels SR 1998 Percentiles for body mass index in U.S. children 5 to 17 years of age. J Pediatr 132:211-222

25. Schofield WN 1985 Predicting basal metabolic rate, new standards and review of previous work. Hum Clin Nutr 39(suppl 1):5-41

26. Moon JK, Vohra FA, Valerio Jimenez OS, Puyau MR, Butte NF 1995 Closed-loop control of carbon dioxide concentration and pressure improves response of room respiration calorimeters. J Nutr 125:220-228

27. de Weir JB 1949 New methods for calculating metabolic rate with special reference to protein metabolism. J Physiol (Lond) 109:1-9

28. Sunehag A, Ewald U, Gustafsson J 1992 Extremely preterm infants ( $<28$ weeks) are capable of gluconeogenesis from glycerol on their first day of life. Pediatr Res 36:553-557

29. Fjeld CR, Cole FS, Bier DM 1992 Energy expenditure, lipolysis, and glucose production in preterm infants treated with theophylline. Pediatr Res 32:693-698
30. Kalhan SC, Trivedi R, Singh S, Chandramouli V, Schumann WC, Landau BR 1995 A micromethod for the measurement of deuterium bound to carbon-6 of glucose to quantify gluconeogenesis in vivo. J Mass Spectrom 30:1588-1592

31. Muntz JA, Carrol RE 1960 A method for converting glucose to fructose. J Biol Chem 235:1258-1260

32. Wong WW, Clarke LL, Llaurador M, Klein PD 1992 A new zinc product for the reduction of water in physiological fluids to hydrogen gas for ${ }^{2} \mathrm{H} /{ }^{1} \mathrm{H}$ isotope ratio measurements. Eur J Clin Nutr 46:69-71

33. Bier DM, Arnold KJ, Sherman WR, Holland WH, Holmes WF, Kipnis DM 1977 In vivo measurement of glucose and alanine metabolism with stable isotope tracers. Diabetes 26:1005-1015

34. Bougnères PF 1987 Stable isotope tracers and the determination of fuel fluxes in newborn infants. Biol Neonate 52:87-96

35. Avogaro A, Bristow JD, Bier DM, Cobelli C, Toffolo G 1989 Stable-label intravenous glucose tolerance test minimal model. Diabetes 38:1048-1055

36. Cobelli C, Toffolo G, Bier D, Nosadini R 1987 Models to interpret kinetic data in stable isotope tracer studies. Am J Physiol 253:E551-E564

37. Cobelli C, Toffolo G, Foster DM 1992 Tracer-to-tracee ratio for analysis of stable isotope tracer data: link with radioactive kinetic formalism Am J Physiol 262:E968 E975

38. Cobelli C, Vicini P, Toffolo G, Caumo A 1997 The hot IVGTT minimal models: simultaneous assessment of disposal indices and endogenous glucose production. In: Bergman RN, Lovejoy JC (eds) The minimal model approach and determinants of glucose tolerance. Louisiana State University Press, Baton Rouge, pp 202-239

39. Toffolo G, De Grandi F, Cobelli C 1995 Estimation of $\beta$-cell sensitivity from intravenous glucose tolerance test C-peptide data: knowledge of the kinetics avoids errors in modeling the secretion. Diabetes 44:845-854

40. Barret PHR, Bell BM, Cobelli C, Golde H, Schumitzky A, Vicini P, Foster D 1998 SAAMII simulation, analysis and modeling software for tracer and pharmacokinetic studies. Metabolism 47:484-492

41. Galster AD, Clutter WE, Cryer PE, Collins JA, Bier DM 1981 Epinephrine plasma thresholds for lipolytic effects in man: measurements of fatty acid transport with [1-13C]palmitic acid. J Clin Invest 67:1729-1738

42. Boyd E 1962 Organ weights from birth to maturity. In: Altman PL, Dittmer DS (eds) Growth. Federation of American Societies for Experimental Biology, Washington, p 346

43. Haymond MW, Sunehag AL 1999 Controlling the sugar bowl: regulation of glucose homeostasis in children. Metab Endocrinol Clin North Am 28:663-694 